\title{
Effect of previous botulinum neurotoxin treatment on microvascular decompression for hemifacial spasm
}

\author{
Xuhui Wang, M.D., M.S., ${ }^{1}$ Parthasarathy D. Thirumala, M.D., M.S., ${ }^{2,4}$ \\ Aalap Shah, M.D., ${ }^{2}$ Paul Gardner, M.D., ${ }^{2}$ Miguel Habeych, M.D., M.P.H., ${ }^{2}$ \\ Donald J. Crammond, Ph.D., ${ }^{2}$ Jeffrey Balzer, Ph.D., ${ }^{2}$ and Michael Horowitz, M.D. ${ }^{2,3}$ \\ ${ }^{1}$ Department of Neurological Surgery, Xinhua Hospital, Shanghai Jiaotong University School of Medicine, \\ Shanghai, China; Departments of ${ }^{2}$ Neurological Surgery, ${ }^{3}$ Radiology, and ${ }^{4}$ Neurology, University of \\ Pittsburgh, Pennsylvania
}

\begin{abstract}
Object. The objective of this study was to investigate the clinical characteristics, intraoperative findings, complications, and outcomes after the first microvascular decompression (MVD) in patients with and without previous botulinum neurotoxin treatment for hemifacial spasm (HFS).

Methods. The authors analyzed 246 MVDs performed at the University of Pittsburgh Medical Center between January 1,2000, and December 31, 2007. One hundred and seventy-six patients with HFS underwent botulinum neurotoxin injection treatment prior to first MVD (Group I), and 70 patients underwent their first MVD without previous botulinum neurotoxin treatment (Group II). Clinical outcome data were obtained immediately after the operation, at discharge, and at follow-up. Follow-up data were collected from 177 patients with a minimum follow-up period of 9 months (mean $54.48 \pm 27.84$ months).

Results. In 246 patients, $89.4 \%$ experienced immediate postoperative relief of spasm, $91.1 \%$ experienced relief at discharge, and $92.7 \%$ experienced relief at follow-up. There was no significant difference in outcomes and complications between Group I and Group II $(\mathrm{p}>0.05)$. Preoperatively, patients in Group I had higher rates of facial weakness, tinnitus, tonus, and platysmal involvement as compared with Group II $(\mathrm{p}<0.05)$. The posterior inferior cerebellar artery and vertebral artery were intraoperatively identified as the offending vessels in cases of vasculature compression in a significantly greater number of patients in Group II compared with Group I ( $\mathrm{p}=0.008$ and $\mathrm{p}$ $=0.005$, respectively, for each vessel). The lateral spread response (LSR) disappeared in $60.48 \%$ of the patients in Group I as compared with $74.19 \%$ in Group II $(\mathrm{p}>0.05)$. No significant differences in complications were noted between the 2 groups.

Conclusions. Microvascular decompression is an effective and safe procedure for patients with HFS previously treated using botulinum neurotoxin. Intraoperative monitoring with LSR is an effective tool for evaluating adequate decompression.

(http://thejns.org/doi/abs/10.3171/2012.11.FOCUS12373)
\end{abstract}

\section{KEY WORDS • hemifacial spasm • microvascular decompression • botulinum neurotoxin • lateral spread response}

$\mathrm{H}$ EMIFACIAL spasm presents as an involuntary contraction of the muscles on either side of the face, ${ }^{1}$ which occurs secondary to compression of the facial nerve by a vascular loop at the root exit zone. ${ }^{4,5}$ Traditionally, HFS treatment includes several approaches such as anticonvulsant medications, and chemical or nerve decompression. Among them, the retromastoid craniotomy and facial nerve MVD has been proven to be an effective cure for patients. ${ }^{17,24,27}$ Since the use of botulinum neurotoxin in HFS was approved by the US FDA in 1989, it has been used as a minimally invasive treatment option for HFS. ${ }^{12}$ Botulinum neurotoxin type $\mathrm{A}$, the most common-

\footnotetext{
Abbreviations used in this paper: AICA $=$ anterior inferior cerebellar artery; EMG = electromyography; HFS = hemifacial spasm; LSR = lateral spread response; $\mathrm{MVD}=$ microvascular decompression; PICA = posterior inferior cerebellar artery; $\mathrm{VA}=$ vertebral artery.
}

ly used botulinum neurotoxin for HFS, produces muscle atrophy that only persists for 3-4 months, so almost all of these patients undergo multiple injections prior to MVD. Although it is not curative, some practitioners, and patients with HFS, prefer botulinum neurotoxin injection therapy. So far, very little has been published regarding the effect of previous botulinum neurotoxin treatment on MVD for HFS. In the present study, the main objective was to investigate the characteristics, outcomes, and complications of MVD for HFS after previous botulinum neurotoxin treatment.

\section{Methods}

Study Design

A retrospective study was conducted with institutional review board approval from the University of 


\section{Wang et al.}

Pittsburgh. Of 293 patients with typical HFS, 176 with HFS received botulinum neurotoxin injection treatment prior to regular single MVD (Group I), and 70 patients underwent their first MVD but had no previous botulinum neurotoxin treatment (Group II). Clinical outcome data were obtained immediately after the operation, at discharge, and at follow-up. Follow-up was performed by contacting the patients by telephone during June of 2008 . Follow-up data were collected from 177 patients who had a minimum follow-up period of 9 months (mean $54.48 \pm$ 27.84 months).

\section{Microvascular Decompression}

We reviewed the records of patients who had HFS and underwent MVD procedures at the University of Pittsburgh Medical Center between January 1, 2000, and December 31, 2007. The operation was performed using a routine retrosigmoid approach. ${ }^{16,19}$ Short-acting neuromuscular junction blocking medications were used for intubation. No additional paralytic agent was administered during EMG monitoring. The dissection was begun from the caudal cranial nerves, using withdrawal of CSF and gentle exposure of pertinent anatomy with handheld suction. Following careful exposure of the cranial nerve VII-VIII complex, any suspect arteries or veins compressing cranial nerve VII anywhere from the brainstem to beyond the root exit zone were treated. The operation was complete when the nerve no longer demonstrated any visible evidence of vascular compression. After confirming that there were no further offending vessels, the surgeon terminated the procedure and closed the craniotomy in a routine fashion.

\section{Intraoperative Neurophysiological Monitoring and Alarm Criteria}

Lateral spread response is a delayed abnormal muscle response in the mentalis muscle following stimulation of the zygomatic branch of the facial nerve. ${ }^{27}$ During surgery, free-run EMG monitoring of the facial, glossopharyngeal, and vagus nerves was performed, in addition to LSR. All instances of free-run EMG activity, regardless of type (spikes, bursts, and neurotonic discharges), were made audible to and also immediately reported to the surgeon and recorded in the patient record. Auditory nerve function was monitored using brainstem auditory evoked potentials, performed with our institution's alarm criteria. ${ }^{23}$ Physician oversight and interpretation of neurophysiological responses (such as brainstem auditory evoked potentials, lateral spread responses, and electromyography from cranial nerves) was performed using a combined on-site and remote model used by the University of Pittsburgh Medical Center. ${ }^{26}$

\section{Statistical Analysis}

Statistical analyses were performed using SAS version 9.1.2 (SAS Institute). Continuous variables were presented as mean $\pm \mathrm{SD}$ and categorical variables as frequency (\%). Group differences in demographics, clinical characteristics, and outcomes were assessed using chisquare tests, using the Fisher exact test correction when needed. A $\mathrm{p}$ value $\leq 0.05$ was considered statistically significant.

\section{Results}

\section{Demographics}

Two hundred forty-six patients with HFS were reviewed. The mean patient age was $52.25 \pm 12.07$ years (range 17-82 years), with a female:male ratio of 1.8:1 and left:right HFS ratio of 1.2:1. Medical and surgical histories were obtained from each patient undergoing MVD. One hundred and seventy-six patients (71.54\%) received prior botulinum neurotoxin treatment (Group I). In Group I, multiple botulinum neurotoxin treatments were administered to 158 patients with HFS, and the mean duration of improvement per application was 4.5 months. The mean interval from beginning the botulinum neurotoxin application to undergoing MVD was approximately 4 years, and the mean frequency of botulinum neurotoxin injections was approximately 3 per year.

\section{Preoperative Characteristics}

A greater number of patients with facial weakness, tinnitus, tonus, and platysmal involvement were found in Group I as compared with Group II. A significantly greater number of patients had HFS on the left side in Group II than those in Group I. There were no significant statistical differences in any of the other clinical characteristics (such as sex, decreased corneal reflex, decreased hearing, and others) between the 2 groups (Table 1).

\section{Intraoperative LSR Monitoring}

Data regarding intraoperative monitoring of the LSR during MVD were available for $229(93.09 \%)$ of the 246 patients. The LSR disappeared in $101(60.48 \%)$ of the 167 patients in Group I as compared with 46 (74.19\%) of the 62 patients in Group II ( $\mathrm{p}=0.054$; Table 2).

\section{Compressing Vasculature Observed Intraoperatively}

The vessels compressing the root exit zone as identified by the surgeon are summarized in Table 2 . A majority (70.5\%) of patients had multiple compressing vessels. The compression was commonly caused by the AICA, PICA, $\mathrm{VA}$, and some veins in both groups. A significantly greater number of patients had the PICA and VA as the offending vessels intraopertively in Group II as compared with Group I ( $\mathrm{p}=0.008$ and $\mathrm{p}=0.005$, respectively; Table 2$)$.

\section{Operative Outcomes}

In 176 patients (Group I), 91.48\% experienced immediate postoperative relief of spasm, $92.61 \%$ experienced relief at the time of discharge, and $90.40 \%$ had relief at the follow-up period. No significant difference in spasm relief between the 2 groups was observed at the immediate postoperative, discharge, or follow-up stages (Table 2).

\section{Postoperative Complications}

Postoperative complications were observed in both patient groups (Table 3). Complications included hearing loss, balance disorder, CSF leakage, diplopia, headache, and dizziness/vertigo. Three patients had new facial palsy in Group I, which was not documented during the pre- 
Botulinum, microvascular decompression, and hemifacial spasm

TABLE 1: Comparison of preoperative clinical characteristics between Group I and Group II*

\begin{tabular}{|c|c|c|c|}
\hline Variable & Group I & Group II & p Value \\
\hline no. of patients (\%) & $176(100.00)$ & $70(100.00)$ & NA \\
\hline female & $115(65.34)$ & $44(62.86)$ & 0.71 \\
\hline male & $61(34.66)$ & $26(37.14)$ & \\
\hline \multicolumn{4}{|l|}{ HFS side (\%) } \\
\hline It & $87(49.43)$ & $46(65.71)$ & $0.02 \dagger$ \\
\hline $\mathrm{rt}$ & $89(50.57)$ & $24(34.29)$ & \\
\hline botulinum history (\%) & $176(100.00)$ & $0(0.00)$ & NA \\
\hline \multicolumn{4}{|l|}{ previous botulinum treatments (\%) } \\
\hline once & $18(10.23)$ & $0(0.00)$ & NA \\
\hline multiple & $158(89.77)$ & $0(0.00)$ & NA \\
\hline mean botulinum interval \pm SD (yrs) & $3.97 \pm 3.22$ & NA & NA \\
\hline mean botulinum frequency $\pm S D$ (per yr) & $2.89 \pm 1.22$ & NA & NA \\
\hline mean time since last botulinum $\pm \mathrm{SD}$ (mos) & $11.96 \pm 8.26$ & NA & NA \\
\hline mean botulinum relief \pm SD (mos) & $4.5 \pm 2.12$ & NA & NA \\
\hline facial weakness (\%) & $108(61.36)$ & $21(30.00)$ & $<0.001 \dagger$ \\
\hline \multicolumn{4}{|l|}{ House-Brackmann Grade of facial weakness (\%) } \\
\hline$\|$ & $59(33.52)$ & $13(18.57)$ & $0.02 \dagger$ \\
\hline III & $40(22.73)$ & $6(8.57)$ & $0.01 \dagger$ \\
\hline IV & $9(5.11)$ & $2(2.86)$ & 0.73 \\
\hline \multicolumn{4}{|l|}{ preop symptom (\%) } \\
\hline decreased corneal reflex & $40(22.73)$ & $13(18.57)$ & 0.47 \\
\hline tinnitus & $15(8.52)$ & $0(0.00)$ & $0.01 \dagger$ \\
\hline decreased hearing & $20(11.36)$ & $9(12.86)$ & 0.74 \\
\hline tonus & 119 (67.61) & $38(54.29)$ & $0.0497 \dagger$ \\
\hline platysmal involvement & $88(50.00)$ & $21(30.00)$ & $0.004 \dagger$ \\
\hline
\end{tabular}

* In Group I, 176 patients underwent previous botulinum neurotoxin treatment and first MVDs; in Group II, 70 patients underwent their first MVDs but had no previous botulinum neurotoxin treatment. Abbreviation: NA = not applicable.

$\dagger$ Statistically significant $(p<0.05)$.

TABLE 2: Comparison of intraoperative findings including LSR, offending vessels, and outcomes between Groups I and II*

\begin{tabular}{lccl}
\hline Variable & Group I (\%) & Group II (\%) & p Value \\
\hline $\begin{array}{l}\text { LSR disappeared } \\
\text { offending vessels }\end{array}$ & $101 / 167(60.48)$ & $46 / 62(74.19)$ & 0.054 \\
AICA & $96(54.55)$ & $33(47.14)$ & 0.29 \\
PICA & $70(39.77)$ & $41(58.57)$ & $0.008 \dagger$ \\
VA & $39(22.16)$ & $28(40.00)$ & $0.005 \dagger$ \\
vein & $68(38.64)$ & $25(35.71)$ & 0.67 \\
perforator & $36(20.45)$ & $9(12.86)$ & 0.16 \\
HFS resolution & & & \\
postop & $161(91.48)$ & $59(84.29)$ & 0.10 \\
discharge & $163(92.61)$ & $61(87.14)$ & 0.17 \\
follow-up & $113 / 125(90.40)$ & $51 / 52(98.08)$ & 0.11 \\
\hline
\end{tabular}

* Data expressed as number of patients (\%).

$\dagger$ Statistically significant. 
operative phase. There was no significant difference in complications between the 2 groups. Complication rates in using botulinum neurotoxin treatment prior to MVDs were as follows: hearing loss $14.20 \%$, facial weakness $1.70 \%$ ( 2 cases of House-Brackmann Grade II and 1 case of Grade III), balance disorder $6.25 \%$, CSF leakage $2.84 \%$, diplopia $3.41 \%$, headache $6.25 \%$, wound infection $2.27 \%$, and dizziness/vertigo $5.11 \%$.

\section{Discussion}

The use of botulinum neurotoxin type A in HFS was approved by the US FDA in 1989, and since then, in view of growing evidence supporting its efficacy, it has become a standard treatment for HFS. ${ }^{2,8}$ As previously reported in the literature by Barbosa et al., ${ }^{2}$ from 1993 to 2004 a total of 808 injections with botulinum neurotoxin were administered to 54 patients with HFS. The mean duration of improvement per application was 3.46 months and the mean rate of improvement using subjective judgment by the patient was $83 \%$. Botulinum neurotoxin, although a less invasive treatment than surgery, can result in potentially life-threatening allergic reactions and systemic manifestation of toxin adverse effects. ${ }^{3,7}$ Because HFS is a disabling condition, the choice to receive repeated noninvasive local injections of botulinum neurotoxin appears to be more acceptable before MVD surgery is considered. In the present study, we analyzed and compared 2 patients groups, one that underwent botulinum neurotoxin treatment prior to MVD, and another that did not.

Although botulinum neurotoxin is a therapeutic alternative for HFS, it has some unavoidable transitory side effects, such as mild facial paresis (lagophthalmos or lower facial paralysis), ptosis, diplopia, and ecchymosis, disappearing after days or weeks. ${ }^{2,12}$ In our series, there were significantly more patients with preoperative facial weakness in Group I than in Group II. There was a greater number of patients with left HFS in Group II than in Group I, which was inconsistent with the results previously reported by Revuelta-Gutiérrez et al. ${ }^{21}$ In addition, our data reveal a higher incidence of patients with platysma muscle involvement and tonus in the facial muscles, when compared with people with HFS not treated by previous botulinum neurotoxin. ${ }^{22,27}$ More than half of the patients in Group I had platysmal involvement and tonus simultaneously. Although the exact origin of the platysmal involvement or tonus has not been studied or evaluated, it is possible that previous treatment with botulinum neurotoxin could be a cause of platysmal involvement or tonus according to the study. In addition, there were significant differences in preoperative tinnitus in Group I as compared with Group II ( $\mathrm{p}=0.01)$.

Microvascular decompression is a highly accepted and effective method for treatment of patients with HFS. ${ }^{1,4,29}$ Much has been published regarding the high efficacy of MVD for HFS, with cure rates ranging anywhere from approximately $82 \%$ to $92 \%$, and excellent long-term results 10 years after MVD in $84 \%$ of patients. ${ }^{25,30}$ Hemifacial spasm is caused by vascular compression of the root exit zone of the facial nerve. ${ }^{6,20}$ The compression was commonly caused by the AICA, PICA, VA, or some veins or perforators in both groups. In our data, it is interesting that there was a high incidence of the PICA and VA as offending vessels in Group II as compared with Group I.

Based on the spasm relief during the immediate postoperative period, results indicate that intraoperative monitoring is an effective tool in helping identify offending vessels during repeat MVD. ${ }^{14,27}$ Given the significant negative predictive value of LSR monitoring, the surgeon can be reassured that an adequate decompression has been achieved and avoid unnecessary operation time and resultant complications, especially when multiple vessels are involved. ${ }^{9,15,18,28}$ The loss of LSR after MVD was not significantly different between the groups. In our previous study we found that HFS patients treated with botulinum neurotoxin prior to MVD demonstrated higher LSR baseline amplitudes during intraoperative monitoring. ${ }^{12}$ These data could be related to muscle poly-reinnervation after recovery from repeated botulinum neurotoxin use. Based on our previously published results ${ }^{27}$ and the current study, the use of LSR in MVDs may be very valuable, irrespective of botulinum neurotoxin treatment.

The operative complications of MVD for HFS include new or worsening facial weakness, hearing loss, diplopia, headache, balance problem, and CSF leakage..$^{10,13,14}$ In our study there was no significant difference in postoperative

TABLE 3: Comparison of postoperative complications between Group I and Group II*

\begin{tabular}{|c|c|c|c|}
\hline Variable & Group I & Group II & $\mathrm{p}$ Value \\
\hline hearing loss & $25(14.20)$ & $6(8.57)$ & 0.23 \\
\hline House-Brackmann Grade of new facial weakness & $3(1.70)$ & $3(4.29)$ & 0.36 \\
\hline$\|$ & $2(1.14)$ & $2(2.86)$ & 0.32 \\
\hline III & $1(0.57)$ & $1(1.43)$ & 0.49 \\
\hline balance disorder & $11(6.25)$ & $3(4.29)$ & 0.76 \\
\hline CSF leakage & $5(2.84)$ & $1(1.43)$ & 0.68 \\
\hline diplopia & $6(3.41)$ & $5(7.14)$ & 0.30 \\
\hline headache & $11(6.25)$ & $7(10.00)$ & 0.31 \\
\hline wound infection & $4(2.27)$ & $0(0.00)$ & 0.58 \\
\hline dizziness/vertigo & $9(5.11)$ & $0(0.00)$ & 0.06 \\
\hline
\end{tabular}

* Data expressed as number of patients (\%). 


\section{Botulinum, microvascular decompression, and hemifacial spasm}

complications between the 2 groups, consistent with results previously reported..$^{12}$ Based on our data, MVD is an effective and safe procedure for patients with HFS previously treated by botulinum neurotoxin. Study limitations include retrospective analysis of data and lack of objective evaluation of long-term data.

\section{Conclusions}

Microvascular decompression is an effective and safe procedure for patients with HFS previously treated by botulinum neurotoxin. Intraoperative monitoring with LSR is an effective tool for evaluating adequate decompression.

\section{Disclosure}

The authors report no conflict of interest concerning the materials or methods used in this study or the findings specified in this paper.

Author contributions to the study and manuscript preparation include the following. Conception and design: Thirumala. Analysis and interpretation of data: Wang. Drafting the article: Wang. Critically revising the article: Thirumala, Horowitz. Reviewed submitted version of manuscript: Shah, Gardner, Habeych, Crammond, Balzer, Horowitz. Approved the final version of the manuscript on behalf of all authors: Thirumala. Statistical analysis: Wang. Administrative/technical/material support: Thirumala.

\section{Acknowledgment}

The authors acknowledge the collaboration of all of the staff and technical members at the Center for Clinical Neurophysiology (CCN), Department of Neurological Surgery, University of Pittsburgh Medical Center, Pittsburgh, Pennsylvania.

\section{References}

1. Acevedo JC, Sindou M, Fischer C, Vial C: Microvascular decompression for the treatment of hemifacial spasm. Retrospective study of a consecutive series of 75 operated patients-electrophysiologic and anatomical surgical analysis. Stereotact Funct Neurosurg 68:260-265, 1997

2. Barbosa ER, Takada LT, Gonçalves LR, Costa RM, SilveiraMoriyama L, Chien HF: Botulinum toxin type A in the treatment of hemifacial spasm: an 11-year experience. Arq Neuropsiquiatr 68:502-505, 2010

3. Bentivoglio AR, Fasano A, Ialongo T, Soleti F, Lo Fermo S, Albanese A: Outcome predictors, efficacy and safety of Botox and Dysport in the long-term treatment of hemifacial spasm. Eur J Neurol 16:392-398, 2009

4. Campos-Benitez M, Kaufmann AM: Neurovascular compression findings in hemifacial spasm. J Neurosurg 109:416-420, 2008

5. Chang JW, Chang JH, Park YG, Chung SS: Microvascular decompression of the facial nerve for hemifacial spasm in youth. Childs Nerv Syst 17:309-312, 2001

6. Chung SS, Chang JH, Choi JY, Chang JW, Park YG: Microvascular decompression for hemifacial spasm: a long-term follow-up of 1,169 consecutive cases. Stereotact Funct Neurosurg 77:190-193, 2001

7. Cillino S, Raimondi G, Guépratte N, Damiani S, Cillino M, Di Pace F, et al: Long-term efficacy of botulinum toxin A for treatment of blepharospasm, hemifacial spasm, and spastic entropion: a multicentre study using two drug-dose escalation indexes. Eye (Lond) 24:600-607, 2010

8. Costa J, Espírito-Santo C, Borges A, Ferreira JJ, Coelho M,
Moore P, et al: Botulinum toxin type A therapy for hemifacial spasm. Cochrane Database Syst Rev (1):CD004899, 2005

9. Dannenbaum M, Lega BC, Suki D, Harper RL, Yoshor D: Microvascular decompression for hemifacial spasm: long-term results from 114 operations performed without neurophysiological monitoring. J Neurosurg 109:410-415, 2008

10. Fernández-Conejero I, Ulkatan S, Sen C, Deletis V: Intra-operative neurophysiology during microvascular decompression for hemifacial spasm. Clin Neurophysiol 123:78-83, 2012

11. Gill HS, Kraft SP: Long-term efficacy of botulinum a toxin for blepharospasm and hemifacial spasm. Can J Neurol Sci 37: 631-636, 2010

12. Habeych ME, Shah AC, Nikonow TN, Balzer JR, Crammond DJ, Thirumala PD, et al: Effect of botulinum neurotoxin treatment in the lateral spread monitoring of microvascular decompression for hemifacial spasm. Muscle Nerve 44:518524, 2011

13. Jannetta PJ: Outcome after microvascular decompression for typical trigeminal neuralgia, hemifacial spasm, tinnitus, disabling positional vertigo, and glossopharyngeal neuralgia (honored guest lecture). Clin Neurosurg 44:331-383, 1997

14. Kalkanis SN, Eskandar EN, Carter BS, Barker FG II: Microvascular decompression surgery in the United States, 1996 to 2000: mortality rates, morbidity rates, and the effects of hospital and surgeon volumes. Neurosurgery 52:1251-1262, 2003

15. Kong DS, Park K, Shin BG, Lee JA, Eum DO: Prognostic value of the lateral spread response for intraoperative electromyography monitoring of the facial musculature during microvascular decompression for hemifacial spasm. J Neurosurg 106:384-387, 2007

16. Møller AR: Vascular compression of cranial nerves. I. History of the microvascular decompression operation. Neurol Res 20:727-731, 1998

17. Møller AR, Jannetta PJ: Microvascular decompression in hemifacial spasm: intraoperative electrophysiological observations. Neurosurgery 16:612-618, 1985

18. Møller AR, Jannetta PJ: Monitoring facial EMG responses during microvascular decompression operations for hemifacial spasm. J Neurosurg 66:681-685, 1987

19. Møller AR, Møller MB: Microvascular decompression operations. Prog Brain Res 166:397-400, 2007

20. Moussa R, Harfouche D, Samaha E, Rizk T, Nohra G, Okais $\mathrm{N}$ : [Microsurgical facial nerve decompression for hemifacial spasm.] J Med Liban 54:146-151, 2006 (Fr)

21. Revuelta-Gutiérrez R, Vales-Hidalgo LO, Arvizu-Saldaña E, Hinojosa-González R, Reyes-Moreno I: [Microvascular decompression for hemifacial spasm. Ten years of experience.] Cir Cir 71:5-10, 2003 (Span)

22. Samii M, Günther T, Iaconetta G, Muehling M, Vorkapic P, Samii A: Microvascular decompression to treat hemifacial spasm: long-term results for a consecutive series of 143 patients. Neurosurgery 50:712-719, 2002

23. Shah A, Nikonow T, Thirumala P, Hirsch B, Chang Y, Gardner P, et al: Hearing outcomes following microvascular decompression for hemifacial spasm. Clin Neurol Neurosurg 114:673-677, 2012

24. Sindou M, Fischer C, Derraz S, Keravel Y, Palfi S: [Microsurgical vascular decompression in the treatment of facial hemispasm. A retrospective study of a series of 65 cases and review of the literature.] Neurochirurgie 42:17-28, 1996 (Fr)

25. Sindou MP: Microvascular decompression for primary hemifacial spasm. Importance of intraoperative neurophysiological monitoring. Acta Neurochir (Wien) 147:1019-1026, 2005

26. Thirumala PD, Kassasm AB, Habeych M, Wichman K, Chang YF, Gardner P, et al: Somatosensory evoked potential monitoring during endoscopic endonasal approach to skull base surgery: analysis of observed changes. Neurosurgery 69 (1 Suppl Operative):ons64-ons76, 2011

27. Thirumala PD, Shah AC, Nikonow TN, Habeych ME, Bal- 


\section{Wang et al.}

zer JR, Crammond DJ, et al: Microvascular decompression for hemifacial spasm: evaluating outcome prognosticators including the value of intraoperative lateral spread response monitoring and clinical characteristics in 293 patients. J Clin Neurophysiol 28:56-66, 2011

28. Yamashita S, Kawaguchi T, Fukuda M, Watanabe M, Tanaka $\mathrm{R}$, Kameyama S: Abnormal muscle response monitoring during microvascular decompression for hemifacial spasm. Acta Neurochir (Wien) 147:933-938, 2005

29. Zhong J, Li ST, Zhu J, Guan HX, Zhou QM, Jiao W, et al: A clinical analysis on microvascular decompression surgery in a series of 3000 cases. Clin Neurol Neurosurg 114:846-851, 2012

30. Zhong J, Zhu J, Li ST, Li XY, Wang XH, Yang M, et al: An analysis of failed microvascular decompression in patients with hemifacial spasm: focused on the early reoperative findings. Acta Neurochir (Wien) 152:2119-2123, 2010

Manuscript submitted November 12, 2012.

Accepted November 27, 2012.

Current affiliation for Dr. Shah: Department of Anesthesiology, University of Washington Medical Center, Seattle, Washington.

Please include this information when citing this paper: DOI: 10.3171/2012.11.FOCUS12373.

Address correspondence to: Parthasarathy D. Thirumala, M.D., M.S., Center for Clinical Neurophysiology, Department of Neurological Surgery, UPMC Presbyterian, Suite B-400, 200 Lothrop Street, Pittsburgh, Pennsylvania 15213. email: thirumalapd@upmc. edu. 